\title{
Immediate reconstruction with autologous fat grafting: influence in loco regional recurrence in breast cancer
}

\section{Reconstrução imediata com enxerto autólogo de gordura: influência na recorrência local de câncer de mama}

Camile Cesa Stumpf; ; Jorge Villanova Biazus'; Fernando Schun Ângela Erguy Zucatto'; Rodrigo Cericatto'; José Antônio Crespo Cavalheiro'; Andrea Pires Souto Damin'; Márcia Portela Melo'

\begin{abstract}
A B S T R A C T
Objective: to evaluate local and systemic recurrence of breast cancer in patients submitted to autologous fat grafting in the immediate reconstruction after conservative surgery for breast cancer. Methods: this is a historical cohort study comparing 167 patients submitted to conservative surgery without reconstruction (conservative surgery group) with 27 patients submitted to conservative treatment with immediate graft reconstruction, following the Coleman's technique (lipofilling group). All patients had invasive carcinoma and were operated by a single surgeon from 2004 to 2011. The postoperative follow-up time was 36 months. Results: the overall incidence of local recurrence was $2.4 \%$. No patient in the lipofilling group had local recurrence during the study period. For systemic recurrence, the rates obtained were $3.7 \%$ (one patient) for the fat grafting group and $1.8 \%$ (three patients) for the conservative surgery group without reconstruction. Conclusion: there was no significant difference for local or systemic recurrence in the groups studied. Immediate autologous fat grafting appears to be a safe procedure.
\end{abstract}

Keywords: Breast Neoplasms. Neoplasm Recurrence, Local. Breast. Transplantation, Autologous. Reconstruction.

\section{INTRODUCTION}

Autologous fat grafting is widely used in plastic surgery to restore contour, increase volume and improve irradiated skin in breast reconstructive surgery ${ }^{1-4}$. The risk of tumor recurrence is unknown when this type of reconstruction is performed simultaneously to conservative surgery, because there are no studies in the literature that use this method in the immediate breast reconstruction. Rigotti et al. ${ }^{5}$ described local and regional recurrence after radical mastectomy with fat graft reconstruction in $6.5 \%$ of 137 patients in 7.6 years of follow-up. The author considered this incidence comparable to that observed in large randomized trials after mastectomy. Rietjens et al. ${ }^{6}$ evaluated 158 patients who underwent 194 fat grafting procedures. He observed only one case of local recurrence, but probably already existed before fat grafting, since the diagnosis was made only two weeks after the procedure. The data were not considered relevant. Petit et al. ${ }^{7}$, on their turn, conducted a case-control study, in which 321 patients who underwent fat grafting for late breast reconstruction were compared with 642 women with similar cancer treatment, but without reconstruction. Invasive tumors accounted for $89 \%$ of the cases, $61 \%$ of the patients underwent mastectomy and the mean follow-up was 56 months after primary surgery and 26 months after the fat grafting procedure. They diagnosed eight cases of local recurrence in the fat grafting group and 19 in the control group. There was no significant difference in patients with invasive carcinoma. In the group of patients with intraepithelial carcinoma who underwent fat grafting, local recurrence increased $(p<0.001)$. Of the local recurrences in the group of intraepithelial carcinomas, three occurred after mastectomy and one after conservative surgery.

Asystematic reviewby Claro etal..$^{8}$ demonstrated that these three studies evaluated a total of 616 patients (mean follow-up of 45.17 months) with 14 cases of local recurrence $(2.27 \%)$. In most recurrencecases, the initial treatment of breast cancer was mastectomy. They identified no significant differences in the cumulative

1 - Clinics Hospital of Porto Alegre, Breast Unit, Porto Alegre, Rio Grande do Sul State, Brazil. 
incidence of cancer risk for patients undergoing fat graft reconstruction.

Using the same database, in 2013 Petit et al. ${ }^{9}$ exclusively evaluated patients with intraepithelial carcinoma, as they showed a higher risk of recurrence after fat grafting. There were 59 women with intraepithelial carcinoma undergoing fat grafting, and 118 women with no fat grafts as controls. They observed nine local recurrences, six in the fat grafting group and three in the control group ( $18 \%$ vs. $3 \%, p=0.02)$, confirming an increased risk. In the control group, however, there was a lower rate of recurrence compared with the rate generally found in patients with intraepithelial carcinomas, of $1 \%$ per year, suggesting that the different incidence found may not be statistically significant.

The objective of the present study was to compare rates of locoregional and systemic recurrence of breast cancer in patients submitted to autologous fat grafting simultaneously to conservative treatment with patients who underwent conservative treatment without reconstruction.

\section{METHODS}

This is a historical cohort study of patients with invasive breast cancer submitted to conservative surgical treatment between January 2004 and December 2011 in the Mastology Sector of the Clinics Hospital of Porto Alegre. We studied 194 patients, divided into two groups: group 1 or lipofilling group, with 27 patients undergoing breast conservative surgery with immediate autologous fat grafting in the years 2010 and 2011 (year of beginning of the intervention) and group 2 or breast conservative surgery (BCS) group, with 167 patients undergoing conservative surgery without breast reconstruction, from 2004 to 2009. We perfumed the fat grafting by the Coleman technique and applied the fat grafting in different directions in the breast, including the tumor bed. In this technique, fat is liposuctioned from any part of the body, most commonly the abdomen, through a liposuction system under low pressure. This lipospired tissue is centrifuged and separated into three phases: blood, oil and purified adipose tissue. The oil and blood are discarded and the purified adipose tissue is injected into the retroglandular and subcutaneous region in small amounts and in different directions, including the tumor bed. In this way, the contact surface between the injected adipocytes and the receptor tissue is increased, increasing the probability of nutrition and incorporation of the new tissue. Bolus injection should not be performed because the excess fat in one place may not be absorbed, inducing the formation of areas of fatty necrosis. It is mandatory to graft a greater amount of adipose tissue than the defect itself because part of the transferred fat is reabsorbed. In experimental studies, up to $90 \%$ of transplanted adipose tissue may be lost, but clinical observation shows that the mean resorption is between $40 \%$ and $60 \%$.

The patients studied had invasive breast carcinoma, clinical stages I and II, submitted to conservative surgery, with negative margins, and were followed up for 36 months. The follow-up consisted of clinical evaluations every three months, with ultrasound and mammography every six months for evaluation of local recurrence, as well as chest X-ray, abdominal ultrasonography and bone scintigraphy for evaluation of systemic recurrence. We excluded patients who had already been treated for breast cancer. A single observer collected and reviewed the patients' records.

The following variables were studied: age, tumor size, histological grade, staging, tumor type, hormone receptor expression, resection margins status, type of adjuvant treatment and presence or absence of local or systemic recurrence. We also evaluated serious postoperative complications that could delay adjuvant treatment and time to relapse diagnosis.

We entered the data into a SPSS (Statistical Package for Social Sciences, version 18.0) worksheet. For the statistical analysis, we compared the data using the chi-square test for categorical variables and the Student's t or Mann-Whitney tests for continuous variables. We estimated recurrence curves using the Kaplan Meier method, and usedthe log rank test to compare the recurrence curves between groups. This difference has alpha $=0.05$ for a difference of $30 \%$, power of $80 \%$. The results were considered significant at $p<0.05$.

The present study was approved by the Ethics in Research Committee of the Clinics Hospital of Porto Alegre, under number 13-0401, and financed by the Mastology Sector of Clinics Hospital. 


\section{RESULTS}

The evaluation of the clinical and histological characteristics of each group did not reveal any statistically significant difference. The mean age was $53.6 \pm 10.9$ years in the lipofilling group and $56.4 \pm 12.0$ years in the BCS group. All tumors were invasive carcinomas: 173 invasive ductal carcinomas and 21 invasive lobular carcinomas. The mean tumor size was $24.3 \pm 10.5 \mathrm{~mm}$ in the lipofilling group and $20.6 \pm 12.0$ in the BCS group. The mean time between surgery and the beginning of adjuvant treatment was one month in the lipofilling group and two months in the BCS group (Table 1). In the BCS group, 26 patients (15.6\%) underwent neoadjuvant chemotherapy, compared with only one $(3.7 \%)$ in the lipofilling group.

Table 1. Clinical and histological characteristics of the patients with invasive ductal carcinoma who underwent either conservative surgery with lipofilling or only conservative surgery.

\begin{tabular}{|c|c|c|}
\hline & BCS* + Lipofilling $(n=27)$ & $B C S(n=167)$ \\
\hline Age (mean in years) & $53.6 \pm 10.9$ & $56,4 \pm 12.0$ \\
\hline Tumor size (mm) & $24.3 \pm 10.5$ & $20.6 \pm 12.0$ \\
\hline \multicolumn{3}{|l|}{ Histological grading } \\
\hline I & $7(25.9)$ & $38(22.8)$ \\
\hline$\|$ & $9(33.3)$ & $85(50.9)$ \\
\hline III & $11(40,7)$ & $44(26.3)$ \\
\hline \multicolumn{3}{|l|}{ Clinical staging (TNM) } \\
\hline I & $7(25.9)$ & $78(46.7)$ \\
\hline II & $20(74.1)$ & $89(53.3)$ \\
\hline \multicolumn{3}{|l|}{ Histology } \\
\hline IDC & $24(88.9)$ & $149(89.2)$ \\
\hline ILC & $3(11.1)$ & $18(10.8)$ \\
\hline \multicolumn{3}{|l|}{ Estrogen receptor } \\
\hline Present & $22(81.5)$ & $128(76.6)$ \\
\hline Absent & $5(18.5)$ & $39(23.4)$ \\
\hline \multicolumn{3}{|l|}{ Progesterone receptor } \\
\hline Present & $22(81.5)$ & $116(69.5)$ \\
\hline Absent & $5(18.5)$ & $51(30.5)$ \\
\hline \multicolumn{3}{|l|}{ HER2 } \\
\hline Overexpressed & $3(11.1)$ & $19(11.4)$ \\
\hline Not overexpressed & $20(74.1)$ & $137(82.0)$ \\
\hline Undertermined & $4(14.8)$ & $11(6.6)$ \\
\hline Neoadjuvant chemotherapy & $1(3.7)$ & $26(15.6)$ \\
\hline Adjuvant chemotherapy & $17(63.0)$ & $62(37.1)$ \\
\hline Adjuvant radiotherapy & $27(100)$ & $163(97.3)$ \\
\hline Time to start of adjuvant therapy (months) & $1(1-2)$ & $2(1-4)$ \\
\hline
\end{tabular}

Categorical variables described as $n(\%)$; Symmetric quantitative variables described as means \pm standard deviation; Asymmetric quantitative variables described as means (P25-P75); BCS- Breast Conservative Surgery; IDC- invasive ductal carcinoma; ILC- invasive lobular carcinoma.

We identified systemic recurrence in one of recurrence did not reveal any statistically significant patient (3.7\%) in the lipofilling group and in seven (4.2\%) differences between the groups (Table 2).

in the BCS group. Comparison of the different types 
Table 2. Recurrence in the lipofilling and breast conservative surgery groups.

\begin{tabular}{lcc}
\hline & $\mathrm{BCS}^{*}+$ Lipofilling $(\mathrm{n}=27)$ & $\mathrm{BCS}(\mathrm{n}=167)$ \\
\hline $\begin{array}{l}\text { Overall recurrence } \\
\text { Local recurrence }\end{array}$ & $1(3.7)$ & $7(4.2)$ \\
$\quad$ Yes & $7(25.9)$ & $38(22.8)$ \\
No & $9(33.3)$ & $85(50.9)$ \\
Systemic recurrence & & \\
Yes & $7(25.9)$ & $78(46.7)$ \\
No & $20(74.1)$ & $89(53.3)$ \\
\hline
\end{tabular}

Categorical variables described as $n(\%) ;{ }^{\star} B C S$ - Breast Conservative Surgery.

We diagnosed local recurrence in four patients (2.4\%) in the BCS group and none in the lipofilling group. Of the recurrences identified, one presented as a nodule, one with microcalcifications and two with cutaneous presentation. We made the diagnoses of local recurrence by physical examination in three patients and by mammography, inone.

The evaluation of each group, according to the type of recurrence, did not show any differences in the incidence of local and systemic recurrence, and we did not find differences in disease-free survival (Figures 1, 2 and 3).

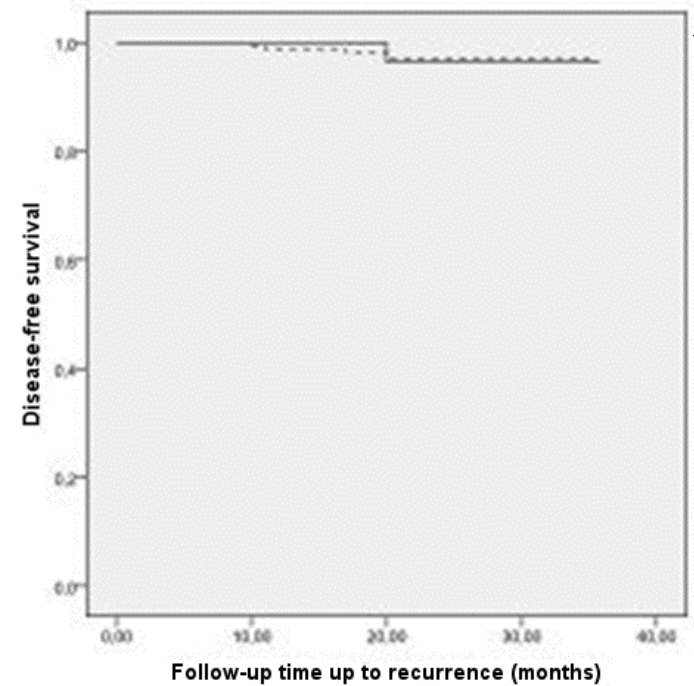

Log rank test ( $p=0.902) ; B C S$ - breast conservative surgery.

Figure 1. Disease-free survival curve in lipofilling and conservative surgery groups up to time of recurrence.

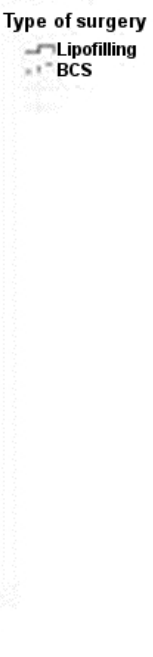

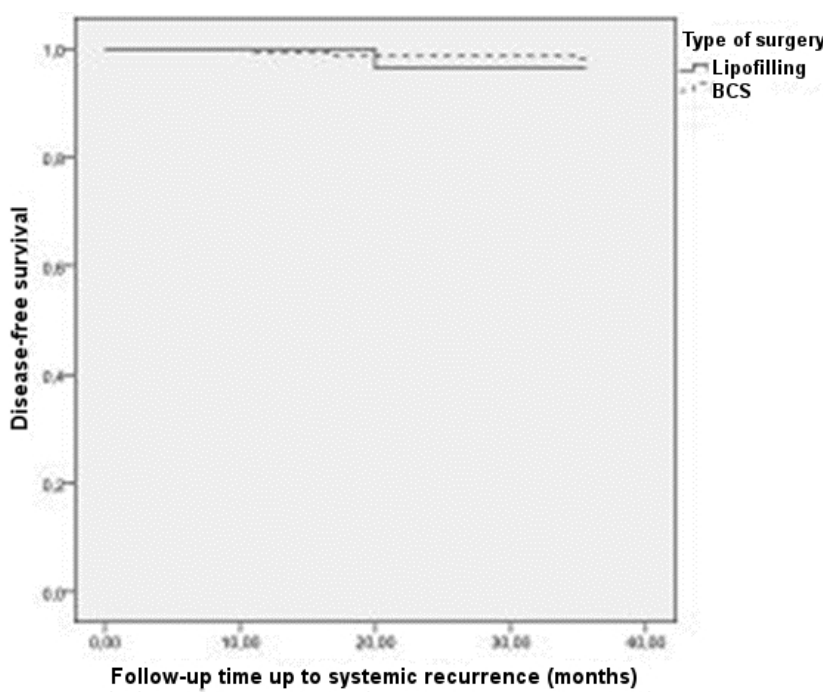

Log rank test ( $p=0.521)$; BCS- breast conservative surgery.

Figure 2. Disease-free survival curve in lipofilling and conservative surgery groups up to time of systemic recurrence.

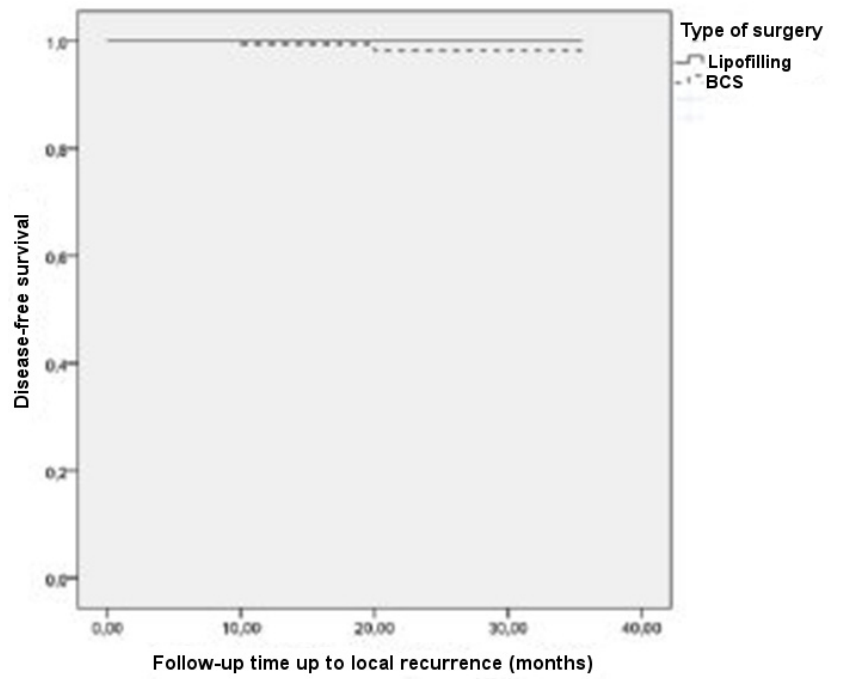

Test log rank ( $p=0.419)$ BCS- breast conservative surgery.

Figure 3. Disease-free survival curve in lipofilling and conservative surgery groups up to time of local recurrence. 


\section{DISCUSSION}

In 2014, Brenelli et al. ${ }^{10}$ published a prospective study of 59 patients who underwent 75 breast fat grafting procedures. All patients had undergone prior conservative treatment for oncological reasons and had a breast defect. They observed immediate complications in three cases, two cases of fat necrosis and one of cellulitis. Three cases of local recurrence were observed (4\%) at 34 months of follow-up, 1.4\% per year, an acceptable rate for conservative surgery. They diagnosed recurrences at different follow-up times, which may suggest that recurrence was not associated with the fat graft procedure.

Biazús et al. ${ }^{11}$ carried out a study at the Clinics Hospital of Porto Alegre, Brazil, in which the autologous fat graft procedure was performed simultaneously with conservative surgery. Twenty patients older than 21 years, clinical stages I and II, underwent conservative surgery with immediate reconstruction with autologous fat according to the Coleman technique. Immediate injection of autologous adipose tissue facilitates repair of hard-to-resolve defects, which are often amplified by radiotherapy, especially in the inner and upper breast quadrants. These patients underwent adjuvant treatment following protocols of patients submitted to conservative surgery and are now under clinical and radiological followup. Autologous fat grafting is a less invasive technique and results in a high level of patient satisfaction ${ }^{12-14}$.

In 2016, Moltó Garcia et al. ${ }^{15}$ published preliminary results of 37 immediate reconstructions of quadrantectomies with autologous fat grafting. They included both benign and malignant tumors. They avoided fat grafting in the same region of the quadrantectomy. All cases studied, with one year of follow up, showed excellent aesthetic results, even after radiotherapy. The complication rate was low and oncological safety was not compromised.

Autologous fat graftinghas been used for correction of body contouring or to correct soft tissue defects in different specialties for many years. In recent years, fat grafting has also been applied to restore breast contour and to stimulate neovascularization of irradiated mammary tissue that is chronically ischemic.
Fat grafts supplement volume in unsatisfactory breast reconstruction results with breast implants, reduces capsular contracture, and improves the quality of breast reconstruction ${ }^{16-19}$. The technique was developed and applied by the Mastology Sector of the Clinics Hospital of Porto Alegre and has shown efficacy in patients with small breasts presenting with tumors in the inner and upper breast quadrants ${ }^{20}$.

In our group of patients submitted to immediate fat grafting and with 36 months of follow-up, we observed no local recurrence and there was only one case of systemic recurrence, comparable to the systemic recurrence rates described in the literature ${ }^{9,21}$. Some studies have shown a greater number of local recurrence in patients with intraductal carcinoma undergoing fat grafting in late reconstruction, but the numbers were not significant, since the control population showed a lower recurrence rate than expected ( $1 \%$ per year $)^{5,7}$. We cannot compared that study to ours because the great majority of patients had undergone mastectomy, whereas the object of our study was only conservative procedures ${ }^{9}$.

We do not have studies about the risk or delay in the diagnosis of relapse in patients who were submitted to immediate fat grafting in the tumor bed of conservative surgery, because the first procedures with this technique were included in the study by Biazús et al. ${ }^{11}$, and these patients are still in follow-up. As all patients were treated following the institutional adjuvant protocols, we believe that there will be no difference between the two groups.

From a cosmetic point of view, Schultz et al. ${ }^{12}$ evaluated 44 patients who underwent fat grafting after conservative surgery or after breast reconstruction to correct deformities. Patients reported improvement in irregularities as well as in breast shape, in addition to increased volume and improved breast tissue consistency. Other authors have obtained the same aesthetic results ${ }^{11,13,14}$. This technique, as demonstrated by de Baclam et al. ${ }^{22}$, has been effective in the correction of deformities in the supero-medial quadrant of the reconstructed breast.

Largo et al..$^{23}$, in a systematic review, reported that seven out of 12 studies aimed at gaining volume after fat grafting had good or excellent results. However, 
only Zocchi and Zuliani ${ }^{24}$ used a standard protocol for satisfaction assessment (excellent, good, fair and insufficient). The other studies did not specify how they assessed patient satisfaction.

Regarding imaging tests, we verified that fat grafting does not cause additional difficulties in the radiological evaluation of suspicious alterations ${ }^{25-28}$. Radiologists can distinguish, with a high level of confidence, calcifications due to fat necrosis from those related to breast cancer ${ }^{29}$. Claro et al. ${ }^{8}$ reported that, in 17 studies with 2,560 patients, the rate of abnormal radiographic changes after fat grafting was 13\% after a 12-month follow-up, data similar to changes that are visualized after any breast surgical procedure. The most common abnormal radiological findings were cysts (74.6\%) and microcalcifications (13.4\%). In addition, there was no statistically significant difference in breast tissue density and in Breast Imaging Reporting and Data System (BIRADS) classification before and after breast fat grafting in 20 patients with no history of breast disease ${ }^{23,25}$.
In any case, failure to diagnose a new cancer is a problem that can occur after any breast surgery. Therefore, the same surveillance used to monitor patients after conservative breast treatment should be used after fat graft reconstruction ${ }^{29}$.

Despite the limitation of the study by the small number of patients in the lipofilling group, the use of fat grafting in conservative surgery seems safe. Induction of a new tumor or accelerated growth of a pre-existing one by fat grafting has also not been confirmed in other studies, as well as there is no scientific evidence of breast cancer or local recurrence after fat grafting in conservative surgery. The technique is promising in patients with invasive cancer. It is simple and provides restoration of shape and volume, with natural texture. This approach may replace more complex procedures, such as intervention in the other breast to obtain symmetry, and is a good alternative in small and medium volume breasts. With the success of the technique, women with larger tumors and with an unfavorable tumor/breast volume ratio for conservative surgery tend to benefit from this type of reconstruction.

\title{
RE S U M O
}

\begin{abstract}
Objetivo: avaliar recorrência local e sistêmica do câncer de mama em pacientes submetidas ao enxerto autólogo de gordura na reconstrução imediata após cirurgia conservadora para o câncer de mama. Métodos: estudo de coorte histórica em que foram comparadas 167 pacientes submetidas à cirurgia conservadora sem reconstrução com 27 pacientes submetidas ao tratamento conservador com reconstrução imediata do enxerto, seguindo técnica de Coleman. Todas as pacientes eram portadoras de carcinoma invasor e foram operadas por um único cirurgião, no período de 2004 a 2011. O tempo de acompanhamento pós-operatório foi 36 meses. Resultados: a incidência global de recidiva local foi 2,4\%. Nenhuma paciente do grupo de lipoenxertia apresentou recorrência local durante o período do estudo. Para recorrência sistêmica, as taxas obtidas foram de 3,7\% (uma paciente) para o grupo lipoenxertia e 1,8\% (três pacientes) para grupo da cirurgia conservadora sem reconstrução. Conclusão: não houve diferença significativa para recorrência local ou sistêmica nos grupos estudados. O enxerto autólogo imediato de gordura parece ser um procedimento seguro.
\end{abstract}

Descritores: Reconstrução. Mama. Neoplasias da Mama. Recidiva Local de Neoplasia. Transplante Autólogo.

\section{REFERENCES}

1. Pearl RA, Leedham SJ, Pacifico MD. The safety of autologous fat transfer in breast cancer: lessons from stem cell biology. J Plast Reconstr Aesthet Surg. 2012;65(3):283-8.

2. Lohsiriwat V, Curigliano G, Rietjens M, Goldhirsch A, Petit JY. Autologous fat transplantation in patients with breast cancer: "silencing" or "fueling" cancer recurrence? Breast. 2011;20(4):351-7.

3. Illouz YG. The fat cell "graft": a new technique to fill depressions. Plast Reconstr Surg. 1986;78(1):122-3.

4. Ogawa M, Hyakusoku H, Ishii N, Ono S. Fat grafting to the breast. Plast Reconstr Surg. 2008;121(2):7023.

5. Rigotti G, Marchi A, Stringhini P, Baroni G, Galiè $M$, Molino AM, et al. Determining the oncological risk of autologous lipoaspirate grafting for post- 
mastectomy breast reconstruction. Aesthetic Plast Surg. 2010;34(4):475-80.

6. Rietjens M, De Lorenzi F, Rossetto F, Brenelli F, Manconi $A$, Martella $S$, et al. Safety of fat grafting in secondary breast reconstruction after cancer. J Plast Reconstr Aesthet Surg. 2011;64(4):477-83.

7. Petit JY, Botteri E, Lohsiriwat $V$, Rietjens $M$, De lorenzi F, Garusi C, et al. Locoregional recurrence risk after lipofilling in breast cancer patients. Ann Oncol. 2012;23(3):582-8.

8. Claro F Jr, Figueiredo JC, Zampar AG, PintoNeto AM. Applicability and safety of autologous fat for reconstruction of the breast. $\mathrm{Br} J$ Surg. 2012;99(6):768-80.

9. Petit JY, Rietjens $M$, Botteri E, Rotmensz N, Bertolini F, Curigliano $G$, et al. Evaluation of fat grafting safety in patients with intraepithelial neoplasia: a matchedcohort study. Ann Oncol. 2013;24(6):1479-84.

10. Brenelli F, Rietjens M, De Lorenzi F, Pinto-Neto A, Rossetto $F$, Martella $S$, et al. Oncological safety of autologous fat grafting after breast conservative treatment: a prospective evaluation. Breast J. 2014;20(2):159-65.

11. Biazús JV, Falcão CC, Parizotto AC, Stumpf CC, Cavalheiro JA, Schuh F, et al. Immediate reconstruction with autologous fat transfer following breastconservative surgery. Breast J. 2015;21(3):268-75.

12. Schultz I, Lindegren A, Wickman M. Improved shape and consistency after lipofilling of the breast: patients' evaluation of the outcome. J Plast Surg Hand Surg. 2012;46(2):85-90.

13. Beck M, Amar O, Bodin F, Lutz JC, Lehmann S, Bruant-Rodier C. Evaluation of breast lipofilling after sequelae of conservative treatment for cancer. A prospective study of ten cases. Eur J Plast Surg. 2012;35(3):221-8.

14. Cigna $E$, Ribuffo $D$, Sorvillo $V$, Atzeni M, Piperno A, Calò PG, et al. Secondary lipofilling after breast reconstruction with implants. Eur Rev Med Pharmacol Sci. 2012;16(12):1729-34.

15. Moltó García R, González Alonso V, Villaverde Doménech ME. Fat grafting in immediate breast reconstruction. Avoiding breast sequelae. Breast Cancer. 2016;23(1):134-40.
16. Hamza A, Lohsiriwat V, Rietjens M. Lipofilling in breast cancer surgery. Gland Surg. 2013;2(1):7-14.

17. Chan CW, McCulley SJ, Macmillan RD. Autologous fat transfer--a review of the literature with a focus on breast cancer surgery. J Plast Reconstr Aesthet Surg. 2008;61(12):1438-48.

18. Rigotti G, Marchi A, Galiè M, Baroni G, Benati D, Krampera $\mathrm{M}$, et al. Clinical treatment of radiotherapy tissue damage by lipoaspirate transplant: a healing process mediated by adipose-derived adult stem cells. Plast Reconstr Surg. 2007;119(5):1409-22; discussion 1423-4.

19. Missana MC, Laurent I, Barreau L, Balleyguier C. Autologous fat transfer in reconstructive breast surgery: indications, technique and results. Eur J Surg Oncol. 2007;33(6):685-90.

20. Coleman SR. Structural Fat Grafting [Chapter 47]. St Louis: Lippincott; 2007. p.480-5.

21. Elder EE, Kennedy CW, Gluch L, Carmalt HL, Janu NC, Joseph MG, et al. Patterns of breast cancer relapse. Eur J Surg Oncol. 2006;32(9):922-7.

22. de Blacam C, Momoh AO, Colakoglu S, Tobias AM, Lee BT. Evaluation of clinical outcomes and aesthetic results after autologous fat grafting for contour deformities of the reconstructed breast. Plast Reconstr Surg. 2011;128(5):411e-8e.

23. Largo RD, Tchang LA, Mele V, Scherberich A, Harder $Y$, Wettstein $R$, et al. Efficacy, safety and complications of autologous fat grafting to healthy breast tissue: a systematic review. J Plastic Reconstr Aesthet Surg. 2014;67(4):437-48

24. Zocchi ML, Zuliani F. Bicompartmental breast lipostructuring. Aesthetic Plast Surg. 2008;32(2):31328.

25. Veber $M$, Tourasse $C$, Toussoun G, Moutran $M$, Mojallal A, Delay E. Radiographic findings after breast augmentation by autologous fat transfer. Plast Reconstr Surg. 2011;127(3):1289-99.

26. Gosset J, Guerin N, Toussoun G, Delaporte T, Delay E. [Radiological evaluation after lipomodelling for correction of breast conservative treatment sequelae]. Ann Chir Plast Esthet. 2008;53(2):17889. (French)

27. Carvajal J, Patiño JH. Mammographic findings after 
breast augmentation with autologous fat injection. Aesthet Surg J. 2008;28(2):153-62.

28. Rubin JP, Coon D, Zuley M, Toy J, Asano Y, Kurita $M$, et al. Mammographic changes after fat transfer to the breast compared with changes after breast reduction: a blinded study. Plast Reconstr Surg. 2012;129(5):1029-38.

29. Coleman SR, Saboeiro AP. Fat grafting to the breast revisted: safety and efficacy. Plast Reconstr Surg. 2007; 119(3):775-85.
Received in: 02/10/2016

Accepted for publication: 09/12/2016

Conflict of interest: none.

Source of funding: Mastology Sector of the Clinics Hospital of Porto Alegre.

\section{Mailing address:}

Camile Cesa Stumpf

E-mail: camystumpf@gmail.com

(cc) BY 


\section{Erratum}

In March/April 2017, the Journal of the Brazilian College of Surgeons [Rev Col Bras Cir. 2017;44(2):17986] published the original article titled "Immediate reconstruction with autologous fat grafting: influence in breast cancerregional recurrence." (http://dx.doi. org/10.1590/0100-69912017002012), by Camile Cesa Stumpf; Jorge Villanova Biazus; Fernando Schuh Ângela
Erguy Zucatto; Rodrigo Cericatto; José Antônio Crespo Cavalheiro; Andrea Pires Souto Damin; Márcia Portela Melo. The following errors were identified:

\section{Title:}

Reads:

"... influence in breast cancerregional recurrence";

Should read:

"... influence in loco regional recurrence in breast cancer.

\section{Tables:}

\section{Reads:}

Table 1. Clinical and histological characteristics of the patients with invasive ductal carcinoma who underwent either conservative surgery with lipofilling or only conservative surgery.

\begin{tabular}{|c|c|c|}
\hline & BCS* + Lipofilling $(n=27)$ & $B C S(n=167)$ \\
\hline Age (mean in years) & $53.6 \pm 10.9$ & $56.4 \pm 12.0$ \\
\hline Tumor size (mm) & $24.3 \pm 10.5$ & $20.6 \pm 12.0$ \\
\hline \multicolumn{3}{|l|}{ Histological grading } \\
\hline I & $7(25.9)$ & $38(22.8)$ \\
\hline$\|$ & $9(33.3)$ & $85(50.9)$ \\
\hline III & $11(40.7)$ & $44(26.3)$ \\
\hline \multicolumn{3}{|l|}{ Clinical staging (TNM) } \\
\hline I & $7(25.9)$ & $78(46.7)$ \\
\hline$\|$ & $20(74.1)$ & $89(53.3)$ \\
\hline \multicolumn{3}{|l|}{ Histology } \\
\hline IDC & $24(88.9)$ & $149(89.2)$ \\
\hline ILC & $3(11.1)$ & $18(10.8)$ \\
\hline \multicolumn{3}{|l|}{ Estrogen receptor } \\
\hline Present & $22(81.5)$ & $128(76.6)$ \\
\hline Absent & $5(18.5)$ & $39(23.4)$ \\
\hline \multicolumn{3}{|l|}{ Progesterone receptor } \\
\hline Present & $22(81.5)$ & $116(69.5)$ \\
\hline Absent & $5(18.5)$ & $51(30.5)$ \\
\hline \multicolumn{3}{|l|}{ HER2 } \\
\hline Overexpressed & $3(11.1)$ & $19(11.4)$ \\
\hline Not overexpressed & $20(74.1)$ & $137(82.0)$ \\
\hline Undertermined & $4(14.8)$ & $11(6.6)$ \\
\hline Neoadjuvant chemotherapy & $1(3.7)$ & $26(15.6)$ \\
\hline Adjuvant chemotherapy & $17(63.0)$ & $62(37.1)$ \\
\hline Adjuvant radiotherapy & $27(100)$ & $163(97.3)$ \\
\hline Time to start of adjuvant therapy (months) & $1(1-2)$ & $2(1-4)$ \\
\hline
\end{tabular}

Categorical variables described as $n$ (\%); Symmetric quantitative variables described as means \pm standard deviation; Asymmetric quantitative variables described as means (P25-P75); BCS- Breast Conservative Surgery; IDC- invasive ductal carcinoma; ILC- invasive lobular carcinoma. 


\section{Should read:}

Table 1. Clinical and histological characteristics of the patients with invasive ductal carcinoma who underwent either conservative surgery with lipofilling or only conservative surgery.

\begin{tabular}{|c|c|c|c|}
\hline & $B C S^{*}+$ Lipofilling $(n=27)$ & $B C S(n=167)$ & $\mathrm{p}$ \\
\hline Age (mean in years) & $53.6 \pm 10.9$ & $56.4 \pm 12.0$ & 0.268 \\
\hline Tumor size (mm) & $24.3 \pm 10.5$ & $20.6 \pm 12.0$ & 0.134 \\
\hline Histological grading & & & 0.194 \\
\hline I & $7(25.9)$ & $38(22.8)$ & \\
\hline$\|$ & $9(33.3)$ & $85(50.9)$ & \\
\hline III & $11(40.7)$ & $44(26.3)$ & \\
\hline Clinical staging (TNM) & & & 0.070 \\
\hline I & $7(25.9)$ & $78(46.7)$ & \\
\hline II & $20(74.1)$ & $89(53.3)$ & \\
\hline Histology & & & 1.000 \\
\hline $\operatorname{IDC} * *$ & $24(88.9)$ & $149(89.2)$ & \\
\hline $\operatorname{ILC} * \star \star$ & $3(11.1)$ & $18(10.8)$ & \\
\hline Estrogen receptor & & & 0.757 \\
\hline Present & $22(81.5)$ & $128(76.6)$ & \\
\hline Absent & $5(18.5)$ & $39(23.4)$ & \\
\hline Progesterone receptor & & & 0.294 \\
\hline Present & $22(81.5)$ & $116(69.5)$ & \\
\hline Absent & $5(18.5)$ & $51(30.5)$ & \\
\hline HER2 & & & 0.330 \\
\hline Overexpressed & $3(11.1)$ & $19(11.4)$ & \\
\hline Not overexpressed & $20(74.1)$ & $137(82.0)$ & \\
\hline Undertermined & $4(14.8)$ & $11(6.6)$ & \\
\hline Neoadjuvant chemotherapy & $1(3.7)$ & $26(15.6)$ & 0.135 \\
\hline Adjuvant chemotherapy & $17(63.0)$ & $62(37.1)$ & 0.020 \\
\hline Adjuvant radiotherapy & $27(100)$ & $163(97.3)$ & 1.000 \\
\hline Time to start of adjuvant therapy (months) & $1(1-2)$ & $2(1-4)$ & 0.041 \\
\hline
\end{tabular}

\section{Reads:}

Table 2. Recurrence in the lipofilling and breast conservative surgery groups.

\begin{tabular}{lcc}
\hline & $\mathrm{BCS}^{*}+$ Lipofilling $(\mathrm{n}=27)$ & $\mathrm{BCS}(\mathrm{n}=167)$ \\
\hline Overall recurrence & $1(3.7)$ & $7(4.2)$ \\
Local recurrence & & \\
$\quad$ Yes & $7(25.9)$ & $38(22.8)$ \\
No & $9(33.3)$ & $85(50.9)$ \\
Systemic recurrence & $7(25.9)$ & $78(46.7)$ \\
Yes & $20(74.1)$ & $89(53.3)$ \\
No & & \\
\hline
\end{tabular}

Categorical variables described as $n(\%) ;{ }^{\star} B C S$ - Breast Conservative Surgery.

\section{Should read:}

Table 2. Recurrence in the lipofilling and breast conservative surgery groups.

\begin{tabular}{lccc}
\hline & $\mathrm{BCS}^{*}+$ Lipofilling $(\mathrm{n}=27)$ & $\mathrm{BCS}(\mathrm{n}=167)$ & $\mathrm{p}$ \\
\hline Overall recurrence & $1(3.7)$ & $7(4.2)$ & 1.000 \\
Local recurrence & & & 1.000 \\
$\quad$ Yes & $0(0.0)$ & $4(2.4)$ & \\
$\quad$ No & $27(100)$ & $163(95.8)$ & 0.454 \\
Systemic recurrence & $1(3.7)$ & $3(1.8)$ & \\
$\quad$ Yes & $26(96.3)$ & $164(98.2)$ & \\
$\quad$ No & & & \\
\hline
\end{tabular}

Categorical variables described as $n(\%) ;{ }^{\star} B C S$ - Breast Conservative Surgery. 